\title{
Atherogenic indices in clinical practice and biomedical research: A short review
}

\author{
Hussein A. Abid ${ }^{1} \oplus$, Zainab S. Abid ${ }^{2}$ and Shireen A. Abid ${ }^{3}$ \\ ${ }^{1}$ Department of Medical Laboratory Technology, Technical Institute of Baquba, Middle Technical University, Baqubah, 32001, Iraq \\ ${ }^{2}$ Ministry of Health, Health Directorate of Diyala, Baqubah, 32001, Iraq \\ ${ }^{3}$ Department of Chemistry, Faculty of Science, University of Diyala, Baquba, 32001, Iraq
}

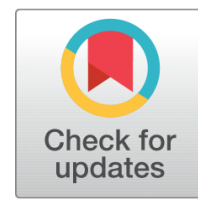

Received 20-03-2021
Revised 22-04-2021
Accepted 10-05-2021
Published 23-05-2021

Corresponding Author Hussein A. Abid

husseinaltameemy@yahoo.com

Department of Medical Laboratory Technology, Te

DOI https://doi.org/10.47419/ bjbabs.v2i02.52

Pages: 60-70

Distributed under the terms of the Creative Commons Attribution-NonCommercial 4.0 International (CC-BY-NC 4.0), which permits use for any non-commercial purpose, distribution, and reproduction in any medium, provided that the original work is properly cited.

Copyright: (C) 2021 Hussein A. Abid, Zainab S. Abid, Shireen A. Abid

\section{OPEN ACCESS}

\section{ABSTRACT}

Cardiovascular diseases (CVD) represent a major cause of mortality and morbidity worldwide. To date, many physicians still requesting traditional lipid profile tests (TG, TC, HDL-C, and LDL-C) to confirm the clinical diagnosis related to CVD. However, using these tests may be inadequate for predicting CVD risk, especially in intermediate risk. For better clinical practice, laboratory diagnostic alternatives should frequently be evaluated and developed by physicians and laboratory scientists. In this review, we sought to focus on the benefits of lipid ratios (CRI-, CRI-II, AIP, AC, and CHOLindex) in supporting clinical diagnosis and how they can be calculated. A literature search in reputed databases (PubMed and Scopus) was performed to attain this aim, and peer-reviewed research articles were included to conduct this review. Short theoretical and practical notes about each index were accordingly included, along with calculation formulas. Thus, the current article can assist new researchers, and young physicians review what supports their knowledge in managing early CVDs.

Keywords atherogenic coefficient, atherogenic Index of plasma, coronary artery disease, dyslipidemia, lipid ratios

\section{INTRODUCTION}

Cardiovascular diseases (CVDs) remain the leading causes of mortality and morbidity worldwide. ${ }^{1}$ Most CVDs such as coronary artery disease (CAD), stroke, myocardial infarction (MI), and peripheral vascular disease (PVD) are developed and frequently attributed to a single risk factor called "dyslipidemia". 2,3 Dyslipidemia can be defined as an elevation in plasma lipids (low-density lipoproteins cholesterol, LDL-C; triglycerides, TGs; or both) or low levels of high-density lipoprotein cholesterol (HDL-C). ${ }^{4}$ Genetics, lifestyle, certain disorders (such as thyroid dysfunction and kidney disease), and drugs are major contributors to cause dyslipidemia. ${ }^{5}$ In addition to its high prevalence in economically advanced societies, dyslipidemia has been recently reported to find its way in semi-urban populations. ${ }^{6}$ 
However, early diagnosis of dyslipidemia before the onset of CVD is a helpful cardiovascular preventive measure. In the evaluation of dyslipidemia, lipid profiles (total cholesterol, TC; LDL-C; HDL-C; and TGs) are mostly considered, with emphasis majorly on LDC-C as "bad cholesterol". ${ }^{7-9}$ Apart from their efficiency in diagnosis, using LDL-C alone, or HDL$\mathrm{C}$ alone in predicting CVD risk may be inadequate especially in intermediate-risk when a someone have one or more risk factors (elevated blood lipids, high plasma glucose level, high blood pressure and overweight) that exceed desirable levels or a positive family history. ${ }^{10-12}$ Thus, suggesting novel biomarkers or more accurate indices by physicians and biomedical scientists is always needed for best clinical practices. Over the past two decades, many reports showed that in cases when the traditional lipid profiles remain normal, several lipid ratios (atherogenic indices) can be diagnostic alternatives that have been shown in predicting the risk of CVD events and the efficacy of therapy. ${ }^{13}$ Among them, atherogenic index of plasma (AIP), ${ }^{14-17}$ Castelli's risk index I (CRI-I) and II (CRI-II), ${ }^{18}$ atherogenic coefficient (AC), ${ }^{9,19,20}$ and cholesterol index (CHOLindex). ${ }^{21,22}$ In this review, the benefits of these indices (ratios) in diagnosing CVD were highlighted and how to calculate each index.

\section{LIPID RATIOS (ATHEROGENIC INDICES)}

\section{Atherogenic index of plasma}

Atherogenic index of plasma (AIP) is an unconventional lipid ratio representing the logarithm of the molar ratio of TGs to HDL-C (Figure 1). ${ }^{23,24}$ Accumulated evidence showed that AIP is an important predictive index with a positive correlation with CVD. In 2010, Onat et al. prospectively evaluated 2676 middle-aged Turkey adults with clinical and laboratory investigations during about 8 years' follow-up and found that AIP is a strong risk factor for CAD in that population. ${ }^{23}$ Moreover, Wang et al. (2021) tested the correlation between AIP and SYNTAX (angiographic grading tool to assess the complexity of CAD) score in the Chinese population. ${ }^{25}$ They concluded that AIP is an independent risk factor for CAD and may assist in CAD prevention. In addition to many reports which have assessed the AIP in different populations to predict CVD in those populations, ${ }^{13,16,17,26-28}$ some researchers suggest a positive correlation with other certain conditions such as acquired premature ejaculation and its severity. ${ }^{29}$ Accordingly, evidence supports that AIP is now ready to be considered in clinical practice and for research purposes and further evaluated.

\section{Castelli's risk indexes (I \& II)}

Castelli's risk indexes (also called cardiac risk indexes) are two lipid ratios, the CRI-I is the ratio of TC to HDL-C (Figure 2), while the CRI-II is the ratio of LDL-C to HDL-C (Figure 3), with notable positive associations with CVD risk. ${ }^{9,18,30}$ They were reported by 


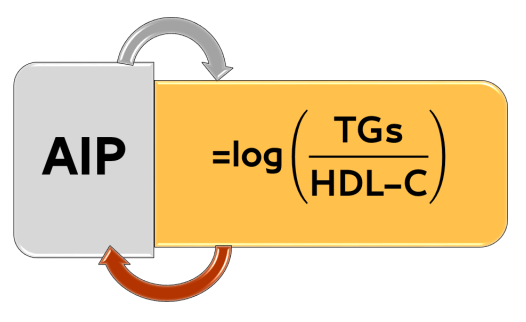

Figure 1 The mathematical equation to calculate the AIP.

William Castelli, at the end of the past century. ${ }^{18}$ Later, many reports assessed and confirmed their positive correlation with $\mathrm{CVD}^{18,24,31-33}$ and some other conditions such as chronic obstructive pulmonary disease (COPD, negative correlation) ${ }^{34}$ and erectile dysfunction. ${ }^{35}$ CRI-I has been particularly shown to reflect coronary plaques formation and the thickness of intima-media in the carotid arteries of young adults. ${ }^{36,37}$ Therefore, physicians should consider CRI-I and II, in clinical practice to predict or assess atherosclerosis and CVD and for further evaluation.

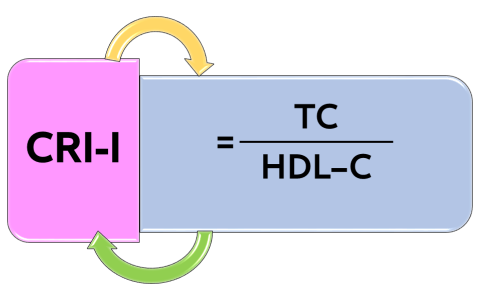

Figure 2 Mathematical equation to calculate CRI-I.

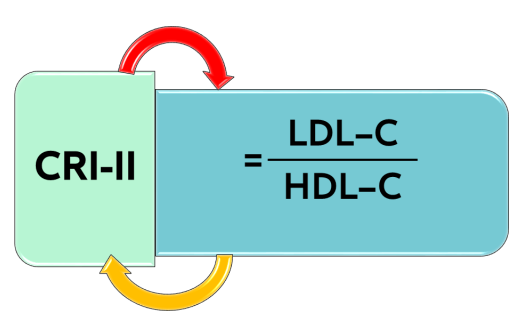

Figure 3 Mathematical equation to calculate CRI-II. 


\section{Atherogenic coefficient}

Atherogenic coefficient (AC) is the ratio of non-HDL cholesterols to HDL-C (Figure 4). ${ }^{9,19}$ It is a diagnostic alternative, which has been used in predicting the risk of developing CV events. ${ }^{38,39}$ In this context, it could be a useful tool for CVD specialists to predict a patient's atherogenic status and for further assessment of this index.

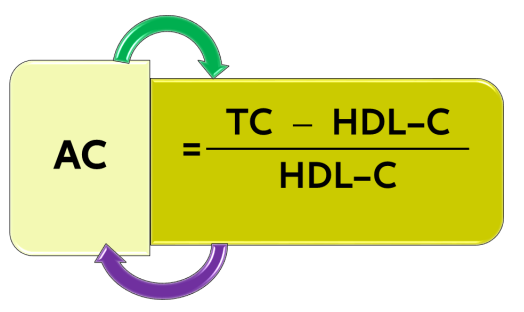

Figure 4 The mathematical equation to calculate AC.

\section{Cholesterol index (CHOLindex)}

Cholesterol index (CHOLindex) is a simple index that predicts the probability of developing CAD with greater accuracy than the other indices. ${ }^{21,22}$ It can be calculated based on LDL-C and HDL-C in individuals with plasma TGs less than $400 \mathrm{mg} / \mathrm{dL}$ (Figure 5). ${ }^{22} \mathrm{In}$ cases when TGs concentration is higher than or equal to $400 \mathrm{mg} / \mathrm{dL}$, the very-low-density lipoprotein cholesterol (VLDL-C) (i.e. TGs $(m g) / 5$ ) should also be included (Figure 6). ${ }^{22}$

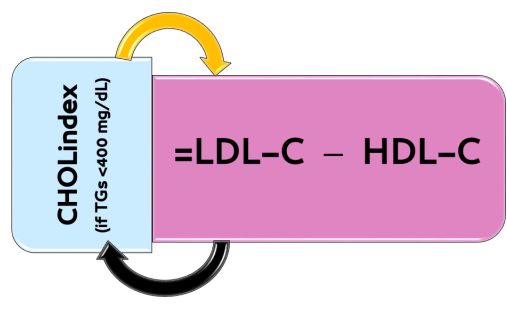

Figure 5 Mathematical equation to calculate CHOLindex if the plasma TGs $<400 \mathrm{mg} / \mathrm{dL}$.

All atherogenic indices can be easily calculated using simple mathematical formulas, which can be applied automatically within automated analytical devices, with no additional costs are required to be paid for calculating them. 


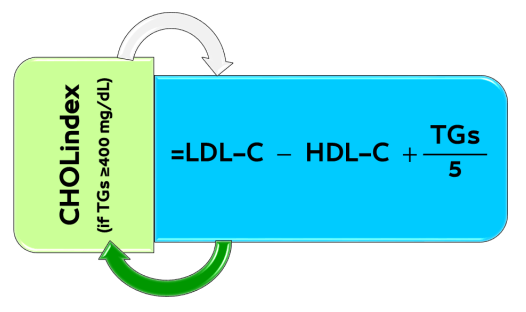

Figure 6 Mathematical equation to calculate CHOLindex if the plasma TGs $\geq 400 \mathrm{mg} / \mathrm{dL}$.

\section{NORMAL RANGES}

In view of limited uses in clinical practices, the normal ranges of atherogenic indices cannot easily set. However, each index range in healthy individuals and patients without CVD in previous reports, based on country and sample size, is listed in (Table 1).

\begin{tabular}{|c|c|c|c|c|}
\hline \multirow[t]{2}{*}{ Index } & \multicolumn{3}{|c|}{ Lab. Findings } & \multirow[t]{2}{*}{ Reference } \\
\hline & Country & No. & Ranges & \\
\hline \multirow[t]{10}{*}{ AIP } & Brazil & 197 & $-0.001 \pm 0.30$ & 19 \\
\hline & Croatia & 95 & $-0.005 \pm 0.269$ & 34 \\
\hline & India & 100 & $0.26 \pm 0.14$ & 40 \\
\hline & Nigeria & 699 & $0.06 \pm 0.002$ & 9 \\
\hline & & 41 & $-0.79 \pm 0.15$ & 30 \\
\hline & Turkey & 51 & $0.28 \pm 0.26$ & 33 \\
\hline & & 48 & $0.35 \pm 0.35$ & 29 \\
\hline & & 32 & $0.54 \pm 0.22$ & 32 \\
\hline & & 32 & $0.62 \pm 0.64$ & 41 \\
\hline & & 19 & $0.52(0.20-0.59)^{*}$ & 31 \\
\hline \multirow[t]{13}{*}{ CRI-I } & Croatia & 95 & $4.15(3.41-5.04)^{*}$ & 34 \\
\hline & India & 100 & $3.04 \pm 0.65$ & 42 \\
\hline & Italy & 56 & $4.33(0.14)^{\ddagger}$ & 20 \\
\hline & Mexico & 49 & Men 4.2(3.56-5.13) ${ }^{\dagger}$ & 42 \\
\hline & & 81 & Women $3.6(3.02-4.27)^{\dagger}$ & 42 \\
\hline & Nigeria & 699 & $3.76 \pm 0.10$ & 9 \\
\hline & & 41 & $2.18 \pm 0.19$ & 30 \\
\hline & Turkey & 127 & $4.7 \pm 1.1$ & 22 \\
\hline & & 48 & $3.19 \pm 2.42$ & 29 \\
\hline & & 19 & $4.27(3.41-5.20)^{*}$ & 31 \\
\hline & & 32 & $4.4 \pm 0.91$ & 32 \\
\hline & & 51 & $3.7(2.4-5.9)^{*}$ & 33 \\
\hline & & 32 & $2.26 \pm 1.54$ & 41 \\
\hline \multirow[t]{3}{*}{ CRI-II } & Croatia & 95 & $2.66(2.00-3.53)^{*}$ & 34 \\
\hline & India & 100 & $1.68 \pm 0.56$ & 42 \\
\hline & Italy & 56 & $2.73(0.11)^{\ddagger}$ & 20 \\
\hline
\end{tabular}




\begin{tabular}{|c|c|c|c|c|}
\hline \multicolumn{5}{|c|}{ Table 1 continued } \\
\hline & Nigeria & 699 & $2.32 \pm 0.09$ & 9 \\
\hline & & 41 & $1.12 \pm 0.18$ & 30 \\
\hline & Turkey & 127 & $2.9 \pm 0.8$ & 22 \\
\hline & & 51 & $2.3(1.1-4.5)^{*}$ & 33 \\
\hline & & 48 & $1.83 \pm 1.54$ & 29 \\
\hline & & 32 & $2.9 \pm 0.72$ & 32 \\
\hline & & 32 & $2.46 \pm 0.86$ & 41 \\
\hline & & 19 & $2.80(2.18-3.52)^{*}$ & 31 \\
\hline \multirow[t]{10}{*}{$\mathrm{AC}$} & Brazil & 197 & $3.25 \pm 1.36$ & 19 \\
\hline & Croatia & 95 & $3.15(2.41-4.04)^{*}$ & 34 \\
\hline & India & 100 & $2.04 \pm 0.65$ & 42 \\
\hline & Nigeria & 699 & $2.76 \pm 0.10$ & 9 \\
\hline & & 41 & $1.18 \pm 0.19$ & 30 \\
\hline & Turkey & 51 & $2.7(1.4-4.9)^{*}$ & 33 \\
\hline & & 48 & $2.49 \pm 2.04$ & 29 \\
\hline & & 32 & $3.4 \pm 0.91$ & 32 \\
\hline & & 32 & $1.27 \pm 1.54$ & 41 \\
\hline & & 19 & $3.27(2.41-4.20)^{*}$ & 31 \\
\hline $\begin{array}{l}\text { CHOLindex } \\
(\mathrm{mmol} / \mathrm{L})\end{array}$ & Nigeria & 699 & $0.78 \pm 0.04$ & 9 \\
\hline
\end{tabular}

$\left(^{\star}\right)=\operatorname{Mean}(95 \% \mathrm{CI}),(\ddagger)=\operatorname{Mean}(\mathrm{SE}),(\dagger)=$ Median $(\mathrm{IQR})$, all other values are presented as Mean \pm SD.

\section{CONCLUSIONS}

Unconventional lipid ratios and indices (AIP, CRI-I, CRI-II, AC, and CHOLindex) are positively associated with CVD. Accordingly, these ratios can assist in predicting various CVD events. CHOLindex, based on the available literature, maybe the more accurate index when compared with the others. All atherogenic indices can be easily calculated using simple mathematical formulas, which can be applied automatically within automated analytical devices with no additional costs.

\section{ABBREVIATIONS}

$\mathrm{AC}$, atherogenic coefficient; AIP, atherogenic index of plasma; CAD, coronary artery disease; CHOLindex, cholesterol index; COPD, chronic obstructive pulmonary disease; CRI-I, Castelli's risk index I; CRI-II, Castelli's risk index II; CVD, cardiovascular disease; HDL-C, high-density lipoprotein cholesterol; IQR, interquartile range; LDL-C, low-density lipoprotein cholesterol; MI, myocardial infarction; PVD, peripheral vascular disease; SD, standard deviation; SE, standard error; TC, total cholesterol; TG, triglycerides; VLDL, very-low density lipoprotein cholesterol. 


\section{ACKNOWLEDGEMENTS}

The authors would like to thank the reviewers and editors who handled this article's original and revised drafts for their efforts and constructive comments.

\section{DECLARATIONS}

\section{Authors' contributions}

Conceptualization: HAA. Data curation, formal analysis, funding acquisition, investigation: N/A. Methodology, project administration: HAA. Resources: HAA. Supervision: HAA. Validation: ZSA \& SAA. Writing-original draft, review \& editing: HAA, ZSA \&SAA. All the authors reviewed and approved the final draft submitted to this journal.

\section{Competing interests}

The authors have no conflict of interest.

\section{Ethical approvals}

Not applicable.

\section{Data availability}

Not applicable.

\section{Funding resources}

No fund was received.

\section{REFERENCES}

1. Nielsen TRH. Dyslipidemia and reference values for fasting plasma lipid concentrations in Danish/North-European White children and adolescents. BMC Pediatr. 2017;17:116. Available from: 10.1186/s12887-017-0868-y.

2. Rached FH, Chapman MJ, Kontush A. An overview of the new frontiers in the treatment of atherogenic dyslipidemias. Clin Pharmacol Ther. 2014;96(1):57-63. Available from: 10.1038/clpt.2014.85.

3. Perk J, De Backer G, Gohlke H, Graham I, Reiner Z, Verschuren WMM. European guidelines on cardiovascular disease prevention in clinical practice (version 2012): The Fifth Joint Task Force of the European Society of Cardiology and Other Societies on Cardiovascular Disease Prevention in Clinical Practice (constituted by re. Eur Heart J. 2012;33(13):1635-1701. Available from: 10.1093/eurheartj/ehs092.

4. Sriwijitkamol A, Sangsawang T. Type of dyslipidemia and achievement of the LDLcholesterol goal in chronic kidney disease patients at the University Hospital. Vasc Health Risk Manag. 2015;563:563-563. Available from: 10.2147/vhrm.s92461. 
5. Chandra KS, Bansal M, Nair T, Iyengar SS, Gupta R, Manchanda SC, et al. Consensus statement on management of dyslipidemia in Indian subjects. Indian Heart J. 2014;66(Supplement 3):1-51. Available from: 10.1016/j.ihj.2014.12.001.

6. Okafor CI. The metabolic syndrome in Africa: Current trends. Indian J Endocrinol Metab. 2012;16(1):56-66. Available from: 10.4103/2230-8210.91191.

7. German CA, Shapiro MD. Assessing atherosclerotic cardiovascular disease risk with advanced lipid testing: State of the science. Eur Cardiol. 2020;15. Available from: 10.15420/ecr.2019.18.

8. Nelson RH. Hyperlipidemia as a risk factor for cardiovascular disease. Prim Care. 2013;40(1):195-211. Available from: 10.1016/j.pop.2012.11.003.

9. Olamoyegun M, Oluyombo R, Asaolu S. Evaluation of dyslipidemia, lipid ratios, and atherogenic index as cardiovascular risk factors among semi-urban dwellers in Nigeria. Ann Afr Med. 2016;15(4):194-194. Available from: 10.4103/1596-3519. 194280.

10. Superko HR, King S. Lipid management to reduce cardiovascular risk: A new strategy is required. Circulation. 2008;117(4):560-568. Available from: 10.1161/ circulationaha.106.667428.

11. Arad Y, Goodman KJ, Roth M, Newstein D, Guerci AD. Coronary calcification, coronary disease risk factors, C-reactive protein, and atherosclerotic cardiovascular disease events. J Am Coll Cardiol. 2005;46(1):158-165. Available from: 10.1016/j.jacc.2005.02.088.

12. Greenland P, Smith SC, Grundy SM. Improving coronary heart disease risk assessment in asymptomatic people: role of traditional risk factors and noninvasive cardiovascular tests. Circulation. 2001;104(15):1863-1870. Available from: 10.1161/ hc4201.097189.

13. Dobiášová $M$, Frohlich J, Šedová $M$, Cheung MC, Brown BG. Cholesterol esterification and atherogenic index of plasma correlate with lipoprotein size and findings on coronary angiography. J Lipid Res. 2011;52(3):566-571. Available from: 10.1194/jlr.p011668.

14. Fernández-Macías JC, Ochoa-Martínez AC, Varela-Silva JA, Pérez-Maldonado IN. Atherogenic Index of Plasma: Novel predictive biomarker for cardiovascular illnesses. Arch Med Res. 2019;50(5):285-294. Available from: 10.1016/j.arcmed.2019. 08.009.

15. Cai G, Shi G, Xue S, Lu W. The atherogenic index of plasma is a strong and independent predictor for coronary artery disease in the Chinese Han population. Medicine. 2017;96(37):e8058-e8058. Available from: 10.1097/md.0000000000008058.

16. Nogay NH. Assessment of the correlation between the atherogenic index of plasma and cardiometabolic risk factors in children and adolescents: might it be superior to the TG/HDL-C ratio? J Pediatr Endocrinol Metab. 2017;30(9):947-955. Available from: 10.1515/jpem-2016-0479.

17. Aguirre M. Triglycerides/High density lipoprotein cholesterol ratio as a cardiometabolic risk marker in children and adolescents from Mérida city, Venezuela. 
Endocrinol Diabetes Nutr (Engl Ed). 2018;65(2):74-83. Available from: 10.1016/j. endinu.2017.10.010.

18. Castelli WP, Abbott RD, McNamara PM. Summary estimates of cholesterol used to predict coronary heart disease. Circulation. 1983;67(4):730-734. Available from: 10.1161/01.cir.67.4.730; https://dx.doi.org/10.1161/01.cir.67.4.730.

19. Nunes SOV. Atherogenic index of plasma and atherogenic coefficient are increased in major depression and bipolar disorder, especially when comorbid with tobacco use disorder. J Affect Disord. 2015;172:55-62. Available from: 10.1016/j.jad.2014.09.038.

20. Brehm A, Pfeiler G, Pacini G, Vierhapper H, Roden M. Relationship between serum lipoprotein ratios and insulin resistance in obesity. Clin Chem. 2004;50(12):23162322. Available from: 10.1373/clinchem.2004.037556.

21. Ulusoy RE. LDL cholesterol measurement in terms of CHOLINDEX. Anatol J Cardiol. 2013;13(6):612. Available from: 10.5152/akd.2013.208.

22. Akpinar O, Bozkurt A, Acarturk E, Seydaoglu G. A new index (CHOLINDEX) in detecting coronary artery disease risk. Anatol J Cardiol. 2013;13(4):315-319. Available from: 10.5152/akd.2013.098.

23. Onat A, Can G, Kaya H, Hergenç G. "Atherogenic index of plasma" ( $\log 10$ triglyceride/high-density lipoprotein - cholesterol) predicts high blood pressure, diabetes, and vascular events. J Clin Lipidol. 2010;4(2):89-98. Available from: 10.1016/ j.jacl.2010.02.005.

24. Gómez-Álvarez E, Verdejo J, Ocampo S, Ponte-Negretti CI, Ruíz E, Ríos MM. The CNIC-polypill improves atherogenic dyslipidemia markers in patients at high risk or with cardiovascular disease: Results from a real-world setting in Mexico. Int J Cardiol Heart Vasc. 2020;29. Available from: 10.1016/j.ijcha.2020.100545.

25. Wang L, Chen F, Xiaoqi C, Yujun C, Zijie L. Atherogenic index of plasma is an independent risk factor for coronary artery disease and a higher SYNTAX score. Angiology. 2021;72(2):181-186. Available from: 10.1177/0003319720949804.

26. MR S, HA C, WG E, M A, AG M, CE LS, et al. Use of the triglyceride/high-density lipoprotein cholesterol ratio to identify cardiometabolic risk: impact of obesity. J Investig Med. 2017;65(2):323-327. Available from: 10.1136/jim-2016-000248.

27. Noumegni SR, Nansseu JR, Bigna JJ, Moor VJA, Assah FK, Dehayem MY, et al. Atherogenic index of plasma and 10-year risk of cardiovascular disease in adult Africans living with HIV infection: A cross-sectional study from Yaoundé, Cameroon. JRSM Cardiovasc Dis. 2017;6:1-7. Available from: 10.1177/ 2048004017740478;

28. Sapunar J, Aguilar-Farías N, Navarro J, Araneda G, Chandía-Poblete D, Manríquez $\mathrm{V}$, et al. High prevalence of dyslipidemia and high atherogenic index of plasma in children and adolescents. Rev Med Chil. 2018;146(10):1112-1122. Available from: 10.4067/S0034-98872018001001112.

29. Ertas K, Nas C. Relationship between atherogenic indices and acquired premature ejaculation. Andrologia. 2021;53(2). Available from: 10.1111/and.13906. 
30. Igharo OG. Lipid profile and atherogenic indices in Nigerians occupationally exposed to e-waste: A cardiovascular risk assessment study. Maedica. 2020;15(2):196-205. Available from: 10.26574/maedica.2020.15.2.196.

31. Tecer D, Sunar I, Ozdemirel AE, Tural R, Kucuksahin O, Dincel AS, et al. Usefullnes of atherogenic indices and Ca-LDL level to predict subclinical atherosclerosis in patients with psoriatic arthritis? Adv Rheumatol. 2019;59(1). Available from: 10.1186/s42358-019-0096-2.

32. Koca TT, Tugan CB, Seyithanoglu M, Kocyigit BF. The clinical importance of the plasma atherogenic index, other lipid indexes, and urinary sodium and potassium excretion in patients with stroke. Eurasian J Med. 2019;51(2):172-176. Available from: 10.5152/eurasianjmed.2019.18350.

33. Çakırca G, Çelik MM. Lipid profile and atherogenic indices and their association with platelet indices in familial Mediterranean fever. Turk Kardiyol Dern Ars. 2018;46:184-190. Available from: 10.5543/tkda.2018.93762.

34. Markelić I, Hlapčić I, Rogić D, Rako I, Samaržija M, Popović-Grle S, et al. Lipid profile and atherogenic indices in patients with stable chronic obstructive pulmonary disease. Nutr Metab Cardiovasc Dis. 2021;31(1):153-161. Available from: 10.1016/ j.numecd.2020.07.039;

35. Culha MG, Canat L, Degirmentepe RB, Albayrak AT, Atalay HA, Merder E, et al. The correlation between atherogenic indexes and erectile dysfunction. Aging Male. 2020;23(5):1232-1236. Available from: 10.1080/13685538.2020.1749996.

36. Nair D, Carrigan TP, Curtin RJ, Popovic ZB, Kuzmiak S, Schoenhagen P, et al. Association of total cholesterol/ high-density lipoprotein cholesterol ratio with proximal coronary atherosclerosis detected by multislice computed tomography. Prev Cardiol. 2009;12(1):19-26. Available from: 10.1111/j.1751-7141.2008.00011.x.

37. Frontini MG, Srinivasan SR, Xu JH, Tang R, Bond MG, Berenson G. Utility of nonhigh-density lipoprotein cholesterol versus other lipoprotein measures in detecting subclinical atherosclerosis in young adults (the Bogalusa heart study). Am J Cardiol. 2007;100(1):64-68. Available from: 10.1016/j.amjcard.2007.01.071.

38. Criqui MH, Golomb BA. Epidemiologic aspects of lipid abnormalities. Am J Med. 1998;105(1A):48-57. Available from: 10.1016/s0002-9343(98)00212-5.

39. Bhardwaj S, Bhattacharjee J, Bhatnagar MK, Tyagi S. Atherogenic index of plasma, Castelli risk index and atherogenic coefficient-new parameters in assessing cardiovascular risk. Int J Pharm Biol Sci. 2013;3(3):359-364.

40. Bora K, Pathak MS, Borah P, Hussain MI, Das D. Association of the apolipoprotein A-I gene polymorphisms with cardiovascular disease risk factors and atherogenic indices in patients from assam, Northeast India. Balk J Med Genet. 2017;20(1):5970. Available from: 10.1515/bjmg-2017-0002;

41. Çalışkan Z. Lipid profile atherogenic indices and their relation of epicardial fat thickness and carotid intima media thickness in Celiac disease. North Clin Istanb. 2019;6:242-247. Available from: 10.14744/nci.2019.54936. 
42. Banik SD, Pacheco-Pantoja E, Lugo R, et al. Evaluation of anthropometric indices and lipid parameters to predict metabolic syndrome among adults in Mexico. Diabetes Metab Syndr Obes. 2021;14:691-701. 